\title{
Halotolerant bacteria mitigate the effects of salinity stress on soybean growth by regulating secondary metabolites and molecular responses
}

Muhammad Aaqil Khan ${ }^{1 *}$ (D), Atlaw Anbelu Sahile ${ }^{1}$, Rahmatullah Jan', Sajjad Asaf ${ }^{2}$, Muhammad Hamayun³, Muhammad Imran ${ }^{1}$, Arjun Adhikari ${ }^{1}$, Sang-Mo Kang ${ }^{1}$, Kyung-Min Kim$^{1}$ and In-Jung Lee ${ }^{1 *}$

\begin{abstract}
Background: Salinity is a major threat to the agriculture industry due to the negative impact of salinity stress on crop productivity. In the present study, we isolated rhizobacteria and evaluated their capacities to promote crop growth under salt stress conditions.

Results: We isolated rhizospheric bacteria from sand dune flora of Pohang beach, Korea, and screened them for plant growth-promoting (PGP) traits. Among 55 bacterial isolates, 14 produced indole-3-acetic acid (IAA), 10 produced siderophores, and 12 produced extracellular polymeric and phosphate solubilization. Based on these PGP traits, we selected 11 isolates to assess for salinity tolerance. Among them, ALT29 and ALT43 showed the highest tolerance to salinity stress. Next, we tested the culture filtrate of isolates ALT29 and ALT43 for IAA and organic acids to confirm the presence of these PGP products. To investigate the effects of ALT29 and ALT43 on salt tolerance in soybean, we grew seedlings in $0 \mathrm{mM}, 80 \mathrm{mM}, 160 \mathrm{mM}$, and $240 \mathrm{mM} \mathrm{NaCl}$ treatments, inoculating half with the bacterial isolates. Inoculation with ALT29 and ALT43 significantly increased shoot length (13\%), root length (21\%), shoot fresh and dry weight (44 and 35\%), root fresh and dry weight (9\%), chlorophyll content (16-24\%), Chl a (843\%), Chl b (13-46\%), and carotenoid (14-39\%) content of soybean grown under salt stress. Inoculation with ALT29 and ALT43 also significantly decreased endogenous ABA levels (0.77-fold) and increased endogenous SA contents (6-16\%), increased total protein (10-20\%) and glutathione contents, and reduced lipid peroxidation (0.8-5-fold), superoxide anion (21-68\%), peroxidase (12.14-17.97\%), and polyphenol oxidase (11.76-27.06\%) contents in soybean under salinity stress. In addition, soybean treated with ALT29 and ALT43 exhibited higher $\mathrm{K}^{+}$uptake (9.34-67.03\%) and reduced $\mathrm{Na}^{+}$content (2-4.5-fold). Genes involved in salt tolerance, GmFLD19 and GmNARK, were upregulated under $\mathrm{NaCl}$ stress; however, significant decreases in GmFLD19 (3-12-fold) and GmNARK (1.8-3.7-fold) expression were observed in bacterial inoculated plants.
\end{abstract}

Conclusion: In conclusion, bacterial isolates ALT29 and ALT43 can mitigate salinity stress and increase plant growth, providing an eco-friendly approach for addressing saline conditions in agricultural production systems.

Keywords: Halotolerant PGPR, Salinity stress, Phytohormones, Antioxidants, Gene expression, Soybean

\footnotetext{
*Correspondence: aqil_bacha@yahoo.com; ijlee@knu.ac.kr

'School of Applied Biosciences, Kyungpook National University, Daegu 41566, Republic of Korea

Full list of author information is available at the end of the article
} 


\section{Background}

Soil salinity is among the most devastating environmental stressors that negatively affect crop production, affecting millions of hectares of land around the world and causing significant economic losses each year [1-3]. Approximately 62 million hectares (20\%) of irrigated land are currently affected by high salt content $[1,2]$, and it has been estimated that more than $50 \%$ of arable land will be salinized by 2050 [4, 5]. Soil salinity limits crop productivity by impairing root growth, nutrient uptake, and metabolic processes [1-3]. The active rhizosphere zone is reduced as a result of impaired root growth and development, affecting nutrient uptake efficiency.

In addition, salinity stress affects physiological, morphological, and biochemical processes, which decrease crop biomass and productivity [2, 3]. Excess $\mathrm{Na}$ and $\mathrm{Cl}$ ions result in ionic imbalances and ion toxicity through competition with $\mathrm{K}$ ions. Ion toxicity interferes with many physiological processes in plants and leads to chlorosis and necrosis [6,7]. Similarly, Na inhibits important cellular processes and enzymatic activities that require $\mathrm{K}$ for functioning by competing with $\mathrm{K}$ for binding sites and disturbing $\mathrm{K}$ homeostasis [6]. It has been suggested that plant survival under salinity stress requires high cytosolic $\mathrm{K}$ concentrations and maintenance of low $\mathrm{Na}$ concentrations in the cytoplasm and cytosol $[8,9]$. Morphological changes under salinity stress have been observed in all growth stages, including germination, seedling, vegetative, and mature stages [10]. Salt stress-induced biochemical changes include the modulation of phytohormones (decreases in the stress hormone abscisic acid [ABA] and increases in the defense hormone salicylic acid [SA]), changes in ion uptake (accumulation or removal of ions), antioxidant enzyme activation, reactive oxygen species (ROS) generation and accumulation, and photosynthetic pathway disruption [2]. On a molecular level, salinity stress in plants also affects gene regulation. Furthermore, salinity stress impedes photosynthesis by affecting chlorophyll and carotenoids and reducing PSII activity [11-13]. A decline in photosynthesis will eventually deplete energy reserves, leading to plant starvation, foliar expansion of leaves, and senescence [14].

Soybean is an economically important legume crop that is cultivated for plant oil, mineral, and protein resources worldwide $[5,15]$. Soybean is semi-tolerant to salinity stress; however, high salinity can decrease soybean yield by inhibiting seed germination and postgermination growth [16-18]. Salinity stress negatively impacts soybean growth, seed quality and quantity, and yield [19]. For soybean, the availability of the whole genome sequence has enhanced our understanding of the basic mechanisms of salinity-related gene expression and regulation [20]. Several soybean genes that confer salinity stress tolerance have been identified [21]. GmFLD19 has been shown to enhance tolerance to salt stress by reducing $\mathrm{Na}$ ion and malondialdehyde content, upregulating antioxidant enzyme activity, and increasing chlorophyll content [15]. Similarly, GmNARK induces ABA production, improving tolerance to salt stress in soybean [22].

Saline conditions present major challenges for agricultural production in many countries [23-25]. Strategies such as traditional breeding, genetic engineering of halotolerant transgenic plants, and chemical applications are used to address the issue of high salinity [26, 27]. However, such methods are not always feasible, and some may even create additional adverse impacts on the ecosystem [28]. Therefore, identifying and developing ecofriendly strategies to manage high salinity are vital for agricultural systems. The use of plant growth-promoting rhizobacteria (PGPR) to elicit mechanisms facilitating plant tolerance to salinity stress has emerged as a promising approach to improve plant adaptation and resource-use efficiency in hostile environments $[17,18$, 29, 30]. PGPR can benefit plant growth and development by producing phytohormones and organic substances that promote growth and increase nutrient availability and uptake $[17,23]$. Several studies have reported the effectiveness of PGPR for improving crop growth under abiotic stress, including salinity stress. Bacterial strains such as Pseudomonas, Burkholdera, Bacillus, and Arthrobacter have been identified as plant growth promoters under saline conditions in crop plants such as cucumber, tomato, wheat, and soybean [23, 29-31]. The purpose of the current study was to isolate, identify, and characterize halotolerant PGPRs. Bacterial isolates ALT29 and ALT43 were selected based on multiple plant growth promotion (PGP) traits. We evaluated the effects of halotolerant isolates ALT29 and ALT43 on soybean growth attributes, ion uptake, ROS generation and antioxidant production, and salt-related gene expression under $\mathrm{NaCl}$ stress at concentrations of 80 $\mathrm{mM}, 160 \mathrm{mM}$, and $240 \mathrm{mM}$.

\section{Results}

\section{Isolation, screening, and identification}

Fifty-five bacterial isolates were isolated (S. Table 1) and screened for plant growth-promoting traits (indole-3acetic acid [IAA], siderophore production, extracellular polymeric substances [EPS] formation, phosphate solubilization, and $\mathrm{NaCl}$ tolerance). The Salkowski reagent results revealed that 14 isolates exhibited IAA activity, 12 isolates exhibited EPS activity and phosphate solubilization, and 10 isolates produced siderophores (S. Fig. 1). Based on multiple PGP traits, we selected 11 isolates to screen at different concentrations of $\mathrm{NaCl}$ (70 $\mathrm{mM}, 140 \mathrm{mM}, 210 \mathrm{mM}$, and $280 \mathrm{mM}$ ). The highest $\mathrm{NaCl}$ 
tolerance was observed in ALT29 and ALT43 (S. Fig. 2), which were, therefore, selected for further investigation and molecular identification. The identification results showed that ALT29 and ALT43 exhibit high sequence similarity with Bacillus aryabhattai and Arthrobacter woluwensis, respectively. The sequences were submitted to NCBI GenBank with accession no. MW077247 and MW077246 (S. Fig. 3).

\section{In vitro IAA quantification of isolates ALT29 and ALT43}

IAA production in the culture filtrate of isolates ALT29 and ALT43 spiked with different concentrations of $\mathrm{NaCl}$ was quantified using GC/MS. ALT29 and ALT43 both produced substantial amounts of IAA, but the highest IAA content was produced by ALT29 (Fig. 1).

\section{Bacterial isolates ALT29 and ALT43 regulate soybean growth under salinity stress}

Salinity stress inhibited the growth attributes and reduced the chlorophyll content of soybean plants. However, the negative effects of salinity were attenuated in soybean plants inoculated with ALT29 and ALT43 (Fig. 2). Compared with the control plants, those exposed to salinity stress exhibited decreases in shoot length (15\%), root length (29\%), shoot fresh and dry weight (49 and 35\%), and root fresh and dry weight (22 and 34\%). Inoculation with isolates ALT29 and ALT43 mitigated salinity stress, increasing the shoot length (13\%), root length (21\%), shoot fresh and dry weight (44 and 35\%), and root fresh and dry weight (9\%) compared with $\mathrm{NaCl}$-stressed plants (Fig. 2; Table 1). Additionally, under normal condition, increases in chlorophyll content (21\%), Chl a (10\%), Chl b (8\%), and carotenoid (8\%) content were observed in ALT29 and ALT43-inoculated soybean plants compared with control plants (Fig. 3). However, when plants were subjected to $\mathrm{NaCl}$ stress (80 $\mathrm{mM}, 160 \mathrm{mM}$, and $240 \mathrm{mM}$ ), a decrease in chlorophyll content (12-42\%), Chl a (18-80\%), Chl b (38-89\%), and carotenoid (19-79\%) content were observed (Fig. 3). Inoculation with halotolerant ALT29 and ALT43 mitigated the $\mathrm{NaCl}$ stress and increased the chlorophyll content (16-24\%), Chl a (8-43\%), Chl b (13-46\%), and carotenoid (14-39\%) content were observed in soybean inoculated plant compared with only $\mathrm{NaCl}$ stressed plants $(80 \mathrm{mM}, 160 \mathrm{mM}$, and 240 mM) (Fig. 3).

\section{Regulation of endogenous phytohormones under salinity stress}

A significant increase in ABA content (1.57-fold) was observed in soybean plants under salinity stress compared to the control (Fig. 4a). However, among plants exposed to $\mathrm{NaCl}$ stress $(80 \mathrm{mM}, 160 \mathrm{mM}$, and $240 \mathrm{mM})$, a decrease in ABA content (0.77-fold) was observed in those inoculated with isolates ALT29 and ALT43 (Fig. 4a). Moreover, SA results were in contrast to ABA results; a $2 \%$ increase in endogenous SA content was observed in plants inoculated with ALT29 and ALT43 under normal conditions. Under $\mathrm{NaCl}$ stress, a 6-16\% increase was observed in soybean plants inoculated with ALT29 and ALT43 (Fig. 4b).

\section{Antioxidant quantification in soybean plants under salinity stress}

Changes in antioxidant content were investigated in soybean plants subjected to $\mathrm{NaCl}$ stress with and without inoculation with isolates ALT29 and ALT43. Malondialdehyde (MDA) content was evaluated to assess the extent of lipid peroxidation (LPO). Higher levels of MDA (2.3-6.3-fold) were observed in soybeans treated with $\mathrm{NaCl}$ stress $(80 \mathrm{mM}, 160 \mathrm{mM}$, and $240 \mathrm{mM})$ compared with ALT29 and ALT43 inoculation (0.8-5-fold) (Fig. 5a). Similarly, superoxide anion (SOA) contents varied in response to the $\mathrm{NaCl}$ treatments (Fig. 5b). However, the production of SOA was significantly inhibited in ALT29 and ALT43-inoculated soybean plants (21-68\%) compared with $\mathrm{NaCl}$-stressed plants (3891\%). Similar trends were observed in peroxidase dismutase (POD) content and polyphenol oxidase (PPO) content, which were lower in salinity stress soybean plants inoculated with isolates ALT29 and ALT43 (Fig. 5c \& d). To further elucidate the ability of ALT29 and ALT43 to mitigate salinity stress, the GSH content in soybean plants was significantly higher $(56-179 \%)$ in ALT29 and ALT43-inoculated plants compared with uninoculated plants (37-136\%) under $\mathrm{NaCl}$ stress (Fig. 5e). In addition, the total protein content significantly decreased (20-43\%) under salinity stress compared with control plants. However, inoculation with halotolerant ALT29 and ALT43 increased the protein content in $\mathrm{NaCl}$-stressed plants by $10-20 \%$ (Fig. $5 f$ ).

\section{geRole of bacterial isolates in ion uptake during salinity stress}

Inductively coupled mass spectrometry (ICP) analysis of $\mathrm{Na}^{+}$and $\mathrm{K}^{+}$content was conducted. Soybean plants treated with $\mathrm{NaCl}(80 \mathrm{mM}, 160 \mathrm{mM}$, and $240 \mathrm{mM})$ exhibited higher $\mathrm{Na}^{+}$content (4-8-fold) (Fig. 6a). However, ALT29 and ALT43-inoculated plants showed significant decreases in $\mathrm{Na}^{+}$content (2-4.5-fold) (Fig. 6a). Compared with $\mathrm{Na}^{+}$, the $\mathrm{K}^{+}$content decreased significantly under salinity stress (24.5-65.39\%) compared with control plants (Fig. 6b). However, $\mathrm{K}^{+}$uptake increased (9.34-67.03\%) in salinity-stressed soybean plants inoculated with ALT29 and ALT43 compared with uninoculated plants (Fig. 6b). 


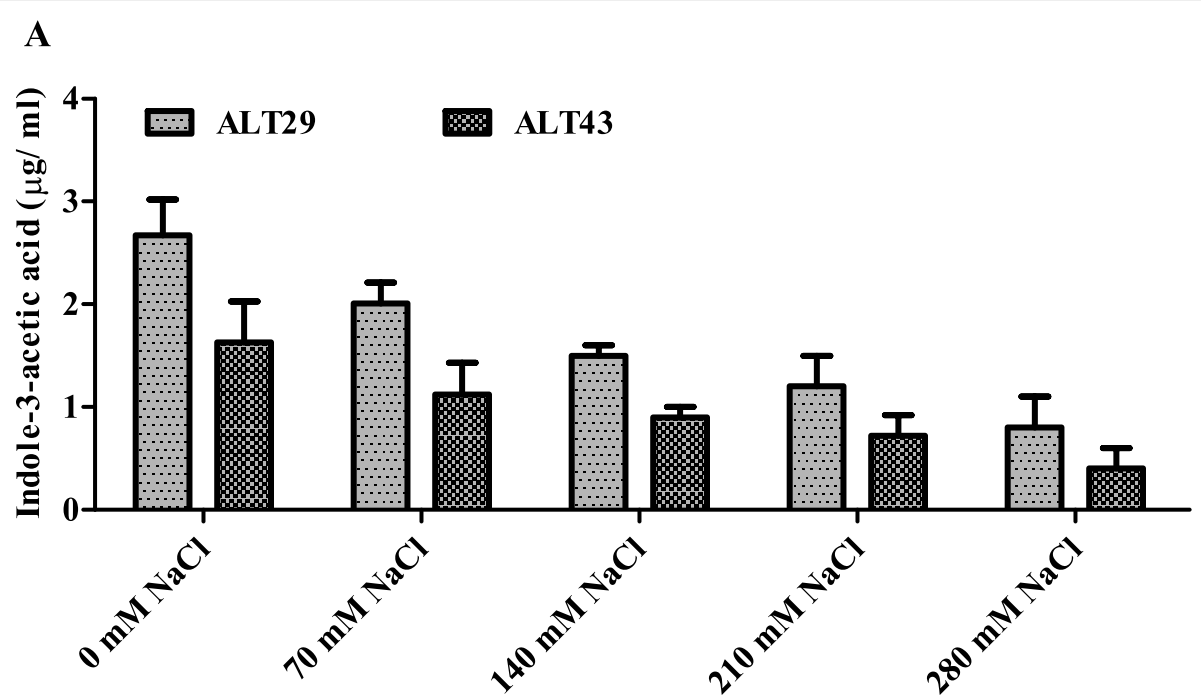

B

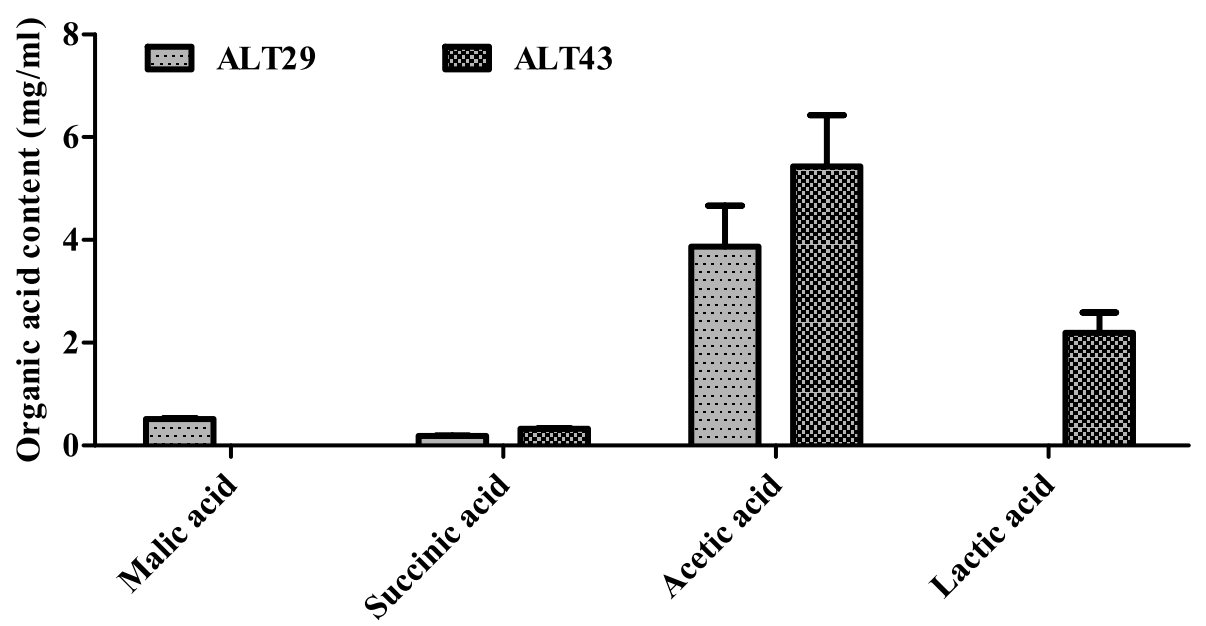

Fig. 1 Quantification of a IAA and $\mathbf{b}$ organic acid content in isolates ALT29 and ALT 43 culture broth using GC/MS-SIM analysis. Data points are the mean of three technical replications and error bars represent standard error. Bars with different letters are significantly different from each other, as evaluated by DMRT analysis

\section{Gene expression under salinity stress and bacteria inoculation}

GmFLD19 was more highly expressed (7-18-fold) in soybean plants exposed to $\mathrm{NaCl}$ stress (Fig. 7a). However, ALT29 and ALT43 inoculation improved soybean adaptability against $\mathrm{NaCl}$ stress, resulting in a significant decrease in GmFLD19 expression (3-12-fold) in soybean plants exposed to $\mathrm{NaCl}$ stress $(80 \mathrm{mM}-240 \mathrm{mM})$ (Fig. 7a). Similarly, a significant increase in the expression of GmNARK was observed in soybean plants exposed to $\mathrm{NaCl}$ stress (2-4.6-fold) (Fig. 7b). However, ALT29 and ALT43 inoculation enhanced soybean resistance to $\mathrm{NaCl}$ stress and reduced the expression of GmNARK (1.8-3.7-fold) in soybean plants exposed to $\mathrm{NaCl}$ stress (Fig. 7b).

\section{Discussion}

Soil salinity is a serious agricultural problem around the world [23-25]. In plants, salinity stress can cause oxidative damage, ion toxicity, and nutritional imbalances that reduce photosynthetic rates, inhibit plant growth, and decrease crop yield and quality [17, 30]. Plants under salinity stress undergo several morphological and physiological changes that impede growth and development [30, 32]. However, beneficial plant growthpromoting rhizobacteria have been demonstrated to play a significant role in alleviating salinity stress in plants, improving crop growth and yield in saline environments $[17,30,32]$. Alleviation of salinity stress by PGPR has been reported in cotton, rice, wheat, tomato and soybean [23, 29-36]. 


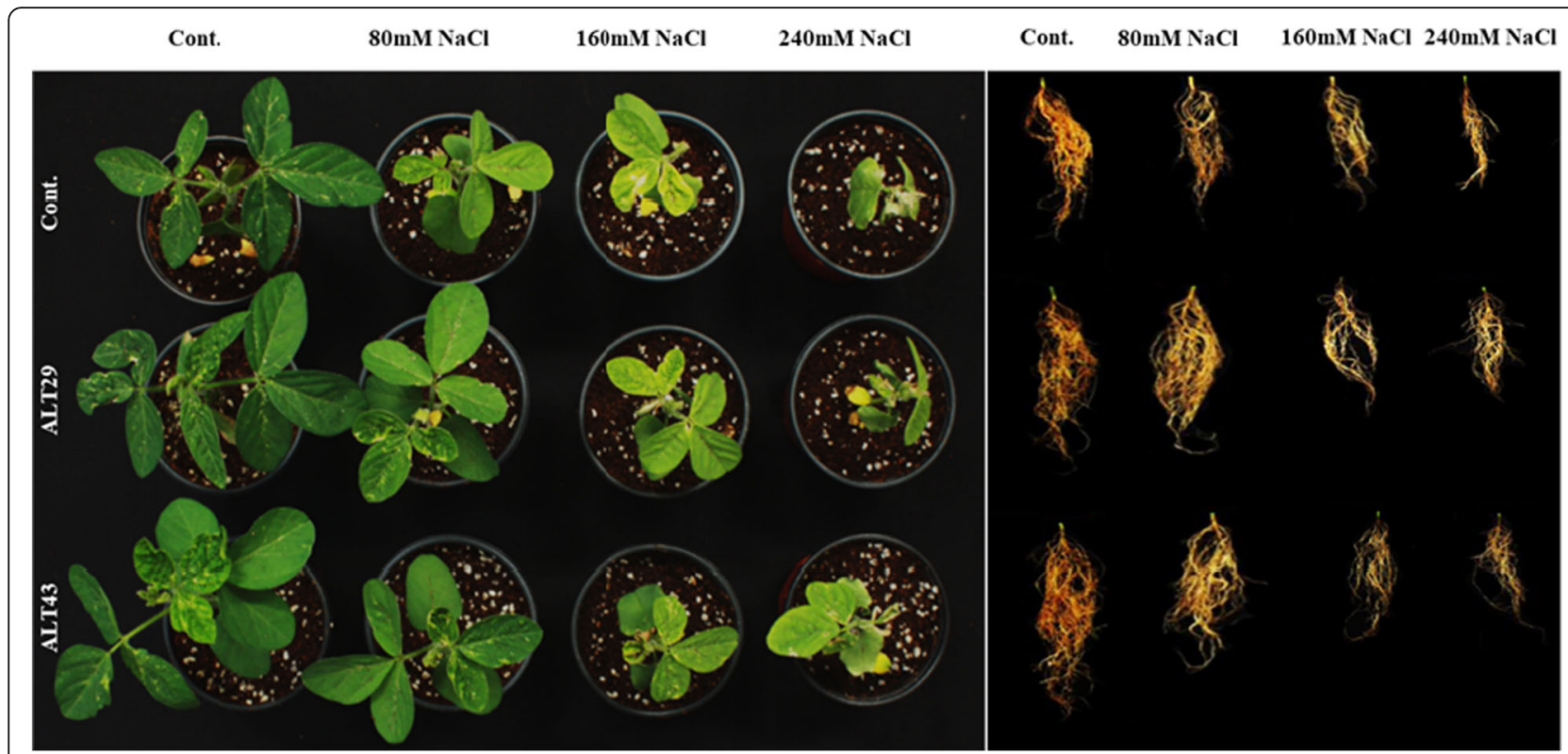

Fig. 2 Effects of bacterial isolates ALT29 and ALT 43 on the growth of soybean plants under normal conditions and $\mathrm{NaCl}$ stress

In this study, soybean plants exposed to $\mathrm{NaCl}$ stress exhibited reduced growth, root and shoot length, and fresh and dry biomass. However, inoculation with bacterial isolates ALT29 and ALT43 mitigated the effects of salinity stress, improving plant-growth attributes in inoculated plants compared to un-inoculated plants (Fig. 2; Table 1). Similarly, chlorophyll content plays a vital role in photosynthesis, however salinity stress affect chlorophyll content depend on level of salinity $[37,38]$. A decrease in chlorophyll content was observed in plants under salt stress. However, $\mathrm{NaCl}$-induced decreases in chlorophyll and carotenoid content were attenuated in soybean plants inoculated with ALT29 and ALT43 (Fig. 3). These results are consistent with previous findings that inoculation with halotolerant PGPR increases chlorophyll content in plants under salinity stress, including Ocimum basilicum [39], Solanum lycopersicum [33], Glycine $\max$ [34], and Oryza sativa [40]. Furthermore Yoo et al. [33] Siddikee et al. [41], Fan et al. [42], and Khan et al. [18] reported Bacillus aryabhattai and Arthrobacter woluwensis against salinity stress in tomato, canola and soybean plants, and reported that plants inoculated with bacteria isolate significantly enhance plant growth, chlorophyll content under $\mathrm{NaCl}$ stress.

Table 1 Growth promoting effect of Isolate ALT29 and ALT43 in soybean under various NaCl stress. The values with \pm show standard deviation (SD) are means of three technical replicates. Value in columns followed by different letters are significantly different as evaluated by DMRT analysis

\begin{tabular}{lllllll}
\hline & SL(cm) & RL(cm) & SFW(g/3P) & RFW(g/3P) & SDW(g/3P) & RDW(g/3P) \\
\hline Cont. & $20.26 \pm 1.4$ & $24.16 \pm 5.34$ & $16.75 \pm 0.75$ & $6.50 \pm 0.55$ & $1.86 \pm 0.45$ & $0.51 \pm 0.08$ \\
ALT29 & $23 \pm 2.0$ & $25.46 \pm 4.88$ & $17.22 \pm 1.07$ & $8.54 \pm 1.36$ & $2.53 \pm 0.45$ & $0.67 \pm 0.03$ \\
ALT43 & $22.06 \pm 1.0$ & $27.83 \pm 5.10$ & $17.07 \pm 1.00$ & $7.79 \pm 0.71$ & $2.42 \pm 0.34$ & $0.63 \pm 0.04$ \\
$80 \mathrm{mM} \mathrm{NaCl}$ & $16.16 \pm 1.04$ & $18.33 \pm 0.76$ & $12.50 \pm 0.50$ & $5.03 \pm 0.50$ & $1.20 \pm 0.2$ & $0.38 \pm 0.01$ \\
$80 \mathrm{mM}+$ ALT29 & $19.96 \pm 0.45$ & $20.33 \pm 1.10$ & $14.74 \pm 0.75$ & $6.87 \pm 0.11$ & $2.02 \pm 0.10$ & $0.42 \pm 0.05$ \\
$80 \mathrm{mM}+$ ALT43 & $18.16 \pm 1.04$ & $22.23 \pm 1.07$ & $14.24 \pm 0.96$ & $6.11 \pm 0.25$ & $2.06 \pm 0.12$ & $0.39 \pm 0.11$ \\
$160 \mathrm{mM} \mathrm{NaCl}$ & $11 \pm 1.00$ & $16.83 \pm 0.76$ & $8.52 \pm 0.50$ & $3.69 \pm 0.20$ & $1.01 \pm 0.10$ & $0.42 \pm 0.02$ \\
$160 \mathrm{mM}+$ ALT29 & $14.1 \pm 0.75$ & $19.5 \pm 1.50$ & $9.90 \pm 0.50$ & $4.99 \pm 0.50$ & $1.5 \pm 0.11$ & $0.38 \pm 0.03$ \\
$160 \mathrm{mM}+$ ALT43 & $13 \pm 1.01$ & $20.16 \pm 0.76$ & $10.28 \pm 0.75$ & $5.96 \pm 0.54$ & $1.43 \pm 0.07$ & $0.52 \pm 0.03$ \\
$240 \mathrm{mM} \mathrm{NaCl}$ & $8.36 \pm 0.77$ & $17.5 \pm 0.51$ & $4.22 \pm 0.40$ & $2.66 \pm 0.32$ & $0.92 \pm 0.06$ & $0.34 \pm 0.03$ \\
$240 \mathrm{mM}+$ ALT29 & $10.5 \pm 0.55$ & $20.5 \pm 1.00$ & $7.83 \pm 0.80$ & $3.01 \pm 0.50$ & $1.163 \pm 0.14$ & $0.42 \pm 0.02$ \\
$240 \mathrm{mM}+$ ALT43 & $11.2 \pm 0.43$ & $17.73 \pm 1.02$ & $8.56 \pm 0.51$ & $4.41 \pm 0.35$ & $1.14 \pm 0.05$ & $0.35 \pm 0.01$ \\
\hline
\end{tabular}

SL Shoot length, RL Root length, SFW Shoot Fresh weight, RFW Root Fresh weight, SDW Shoot Dry weight, RDW Root Dry weight 


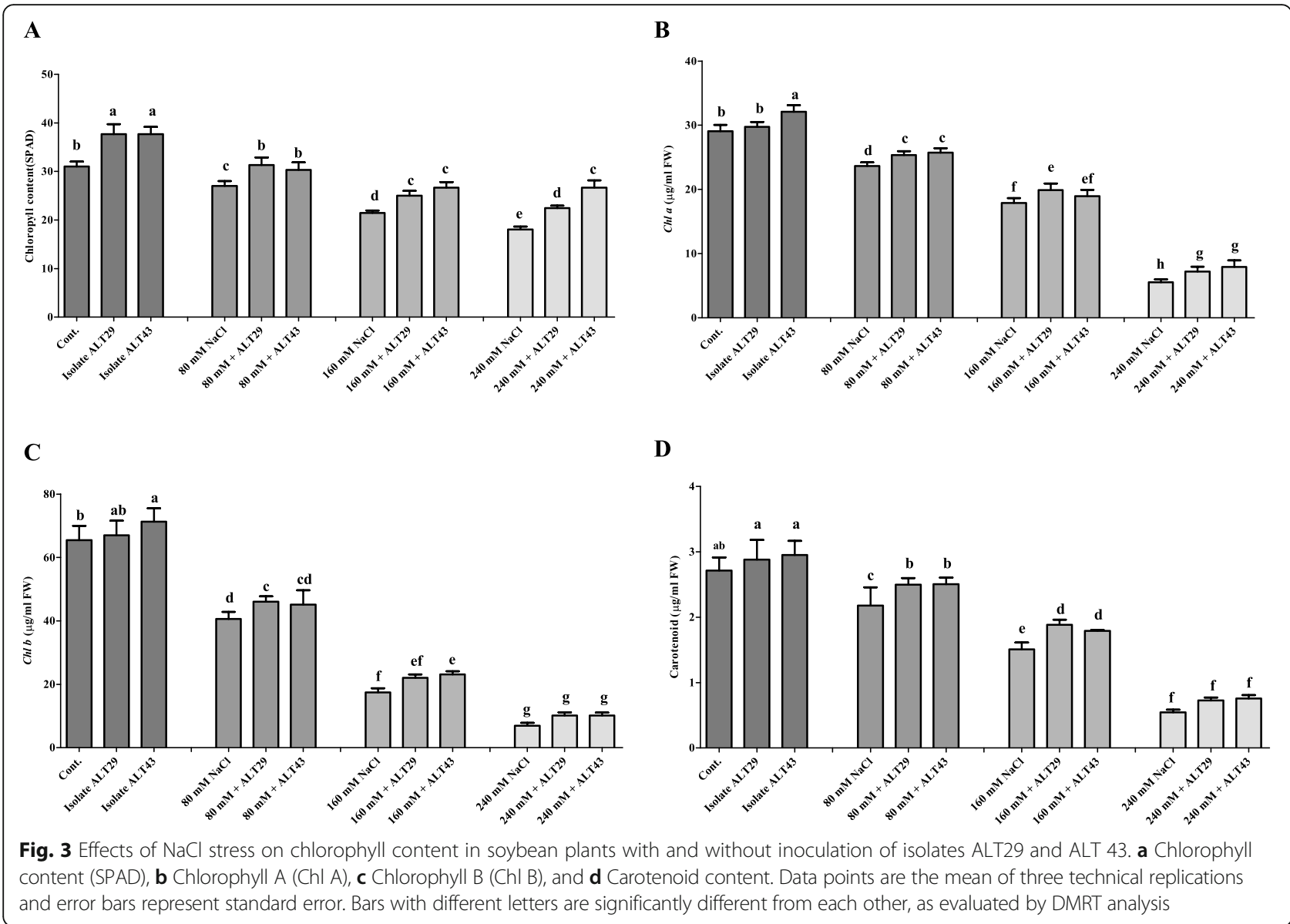

The beneficial effects of the selected halotolerant bacterial isolates (ALT29 and ALT43) on soybean growth may be attributed to the salinity tolerance and plant growth-promoting traits (EPS formation, organic acid, and IAA production) exhibited by these isolates (S. Fig. 1 and Fig. 1). Vurukonda [27] and Selvakumar [28] reported that EPS-producing bacteria contribute to the maintenance of salinity tolerance in plants, providing protection against salinity stress [43, 44]. Similarly, organic acids benefit plants by providing an important source of carbon and energy as well as regulating abiotic stress tolerance [45]. The bacteria used in the current study produce several organic acids (Fig. 1b), which have been shown to enhance plant growth. Furthermore, IAA is an essential phytohormone, and numerous studies have demonstrated that IAA-producing halotolerant bacteria improve plant salinity tolerance. In this study, isolates ALT29 and ALT43 produced IAA in LB media with $\mathrm{NaCl}$ (Fig. 1a). Therefore, the growth promotion of saltstressed soybean plants inoculated with ALT29 and ALT43 is likely mediated by these PGP traits.

Salinity stress leads to the accumulation of $\mathrm{Na}$ and $\mathrm{Cl}$, which affects the presence and distribution of other vital elements in plants, reducing physiological activity and plant growth [2,3]. Increased concentrations of $\mathrm{Na}$ ions produce osmotic stress, impacting intercellular $\mathrm{K}$ influx [6]. $\mathrm{K}$ is an essential element for plant growth [46]; the results of this study showed decreases in $\mathrm{K}$ and increases in $\mathrm{Na}$ in soybean plants under salinity stress (Fig. 6). However, inoculation with ALT29 and ALT43 improved K uptake and reduced $\mathrm{Na}$ uptake in $\mathrm{NaCl}$-treated plants (Fig. 6).

In addition, phytohormones are essential signal molecules in plants that are regulated under stress conditions [47, 48]. In particular, salinity stress has been shown to increase the biosynthesis of the phytohormone abscisic acid $[49,50]$. Previous studies show that high endogenous ABA content inhibits the growth of Brassica napus, Zea mays, and Phaseolus vulgaris [47, 48, 51]. Inoculation with halotolerant PGPR modulates abiotic stress, including salinity stress, and reduces ABA biosynthesis $[35,52-54]$. In the current study, we observed a significant increase in endogenous ABA content in soybean plants under $\mathrm{NaCl}$ stress; however, this effect was mitigated by ALT29 and ALT43 inoculation (Fig. 4a). Similarly, salt-stressed Gossypium hirsutum and Triticum aestivum inoculated with salt-tolerant Pseudomonas 

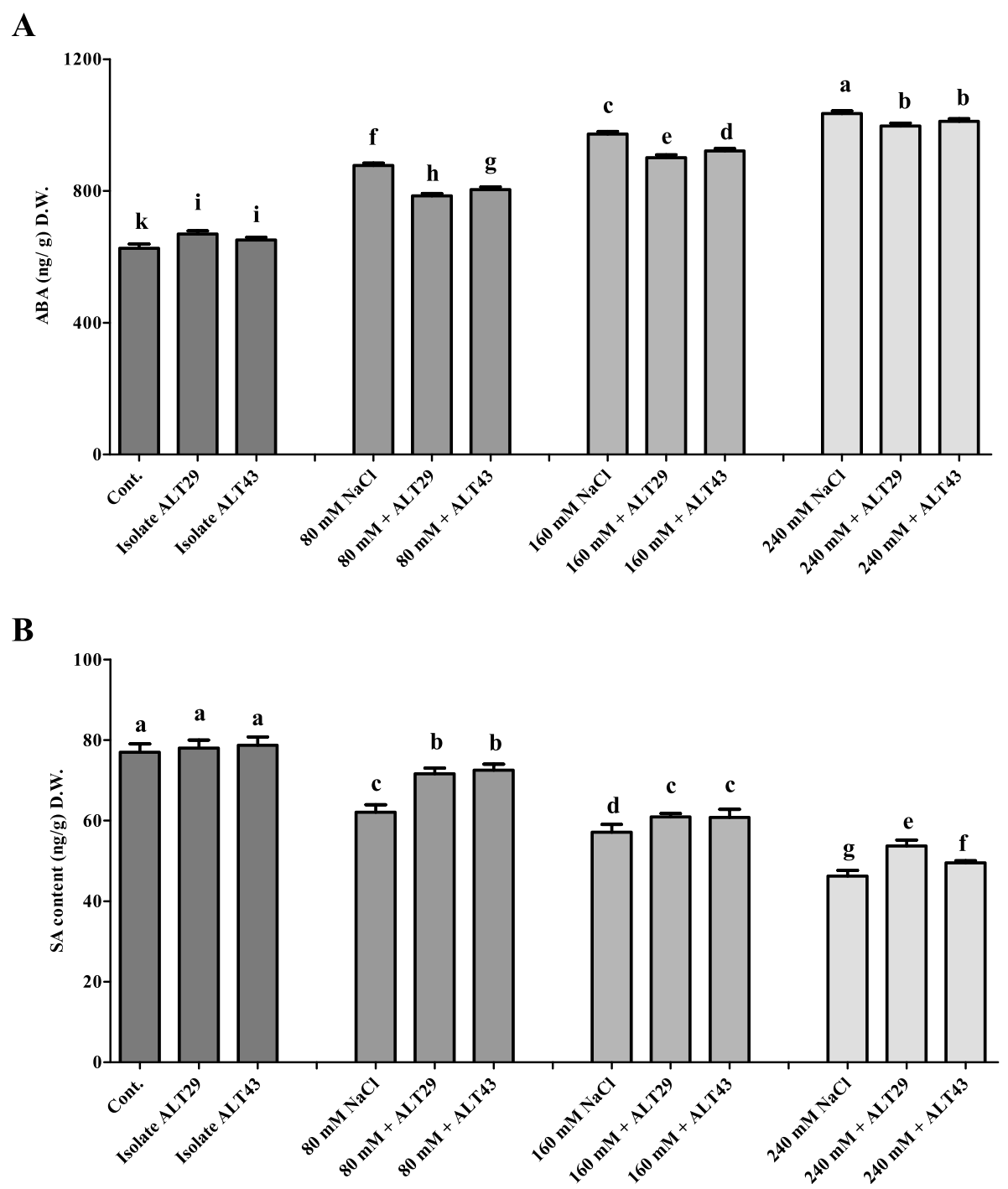

Fig. 4 Endogenous abscisic acid (ABA), and salicylic acid (SA) quantification in soybean plants inoculated with ALT29 and ALT 43. a ABA content and $\mathbf{b}$ SA content under normal conditions and $\mathrm{NaCl}$ stress. Data points are the mean of three technical replicates. Error bars represent standard error. Bars with different letters are significantly different from each other, as evaluated by DMRT

putida, Arthrobacter protophormiae, and Bacillus subtilis exhibited reduced ABA accumulation and enhanced plant growth [32, 36].

Salicylic acid is a defense-signaling phytohormone that acts as an ROS scavenger, protecting plants from oxidative stress [55-57]. Hamayun et al. [3] and Wang et al. [58] reported a decrease in endogenous SA in Glycine max and Iris hexagona under salinity stress. Our results were consistent with these findings in that $\mathrm{NaCl}$ reduced SA content in soybean; however, higher SA contents were observed in soybean plants inoculated with isolates ALT29 and ALT43 (Fig. 4b). Our current finding confirms the previous reports of Kang et al. [59] and Khan et al. $[60,61]$ who reported that bacterial inoculation enhances SA content in plants under abiotic stress.
Accumulation of $\mathrm{Na}$ in plant tissues increases the formation of ROS (superoxide anion, singlet oxygen), disturbs the normal metabolism, and produces cellular toxicity and protein degradation [62]. To mitigate the effects of salinity stress and increased ROS generation, plants activate antioxidant defense systems, such as glutathione reductase (GR), LPO, and other antioxidant enzymes (PPO, POD, TPP) that remove free radicals and protect against cellular stress. Soybean plants inoculated with ALT29 and ALT43 exhibited increases in GSH and TPP content and decreases in LPO, SOA, and PPO content under salinity stress (Fig. 5). Similar results were also observed in maize, rice, and basil plants inoculated with halotolerant bacteria, which exhibited significant increases in ROS-scavenging enzyme activity [39, 40, 63, 64]. 


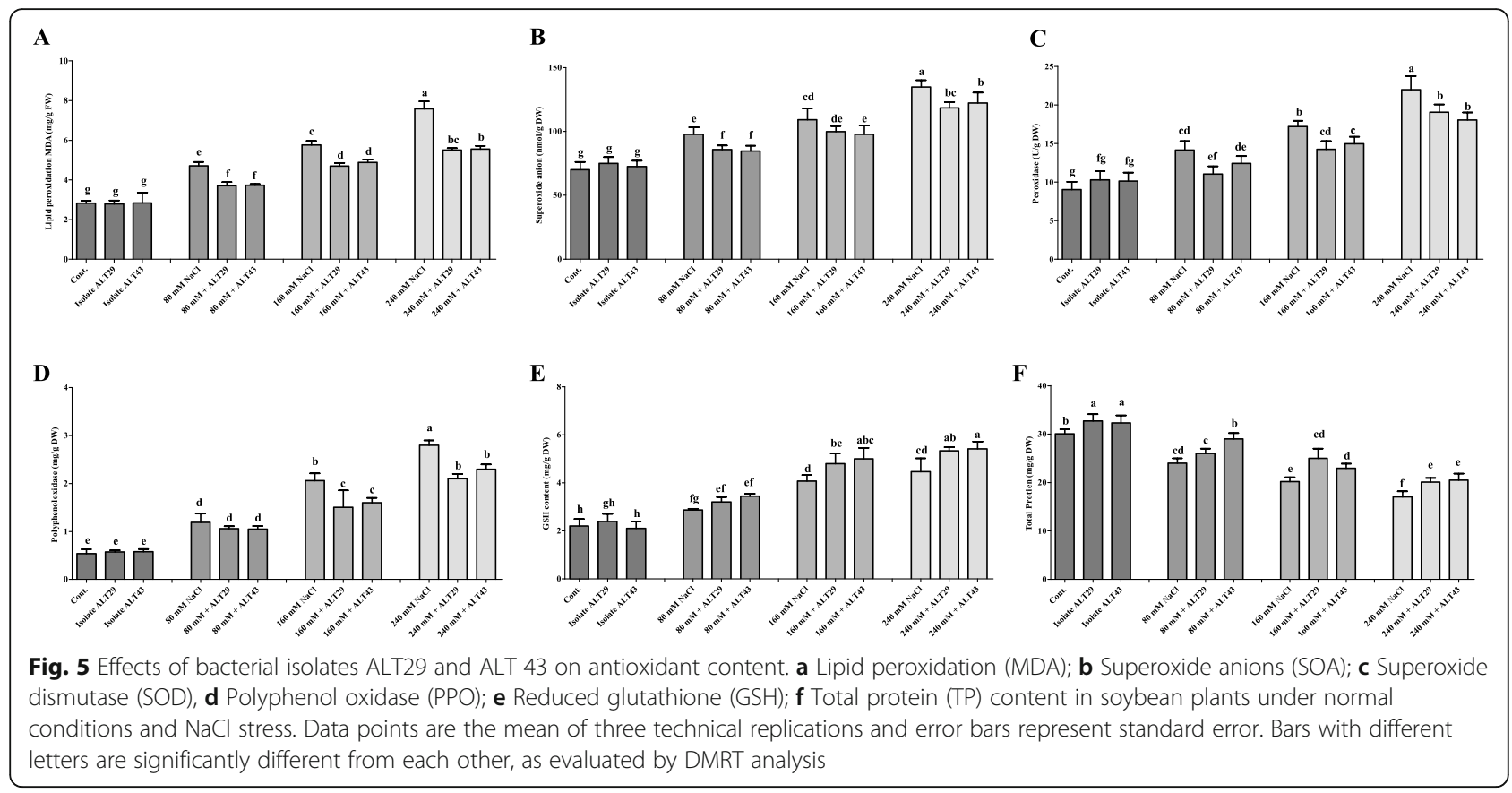

Furthermore, the identification of genes that confer salt tolerance is essential for genetic engineering of halotolerant crop plants for agricultural production in saline environments. A number of candidate genes have been identified and reported in soybean. GmFLD19, a novel group A bZIB gene, was determined to play an important role in abiotic stress tolerance in soybean $[15,65]$. GmNARK (Glycine max nodule autoregulation receptor kinase) also contributes to abiotic stress tolerance and regulates ABA [22]. ABA result of our current investigation showed higher $\mathrm{ABA}$ content in $\mathrm{NaCl}$ stressed soybean plants might be due to induce in relative expression of GmNARK and GmFLD19 (Fig. 5a). Furthermore, Li et al. [15] also report lower Na content in GmFLD19 transgenic soybean plants and report that GmFLD19 might function in regulating absorption of $\mathrm{Na}$ by improving salt tolerance in soybean. Our results showed that salinity stress upregulated the expression of GmFLD19 and GmNARK (Fig. 6). However, inoculation with ALT29 and ALT43 stimulated the expression of GmFLD19 and GmNARK in soybean plants exposed to salinity stress (Fig. 6). Previous reports show that overexpression of GmFLD19 and GmNARK in soybean enhances salinity tolerance by reducing $\mathrm{Na}$ ion and malondialdehyde content and increasing antioxidant activity and chlorophyll content in transgenic soybean [15, 22]. Overexpression of GmFLD19 and GmNARK in soybean indicate that these genes are exemplary candidates for breeding stress-tolerant cultivars $[15,22]$.

\section{Conclusion}

The results of the current study show that halotolerant isolates ALT29 and ALT43 possess plant-growth- promoting traits, including salt tolerance, EPSformation, and organic acid and IAA production. Moreover, ALT29 and ALT43 mitigate the effects of salinity stress and increase growth, biomass, and chlorophyll content in soybean under $\mathrm{NaCl}$ stress $(80 \mathrm{mM}, 160 \mathrm{mM}$, and $240 \mathrm{mM}$ ). The improvement in soybean growth induced by isolates ALT29 and ALT43 can be attributed to the ability of these bacteria to regulate endogenous phytohormones (ABA and SA), antioxidants (GSH, LPO, TPP, PPO, and POD), ion uptake (Na and $\mathrm{K})$, and gene expression (GmFLD19 and GmNARK) under salinity stress. Therefore, we demonstrated that inoculation with ALT29 and ALT43 isolates provides a valuable, ecofriendly, and low-cost biotechnological approach to improve sustainable agricultural production in salt-affected areas.

\section{Methods}

Isolation, screening, and identification

Rhizospheric bacteria were isolated from Pohang beach, South Korea, as previously reported by Khan et al. [17, 18, 23]. Plants root with adherent soil was transferred into conical flask $(99 \mathrm{ml}$ sterilized distilled water and shaken for 3 mints). The sample were diluted through a series of 1-folds dilution, and $0.1 \mathrm{ml}$ of solution was spread on LB agar plates and incubated at $28^{\circ} \mathrm{C}$. Bacterial colonies were collected based on their colony morphology, and preserved in $75 \%$ glycerol stock till further analysis.

All isolates were screened for plant growth-promoting traits such as indole-3-acetic acid, siderophore production, phosphate solubilization, EPS production and $\mathrm{NaCl}$ tolerant. To assess IAA production, the bacterial isolates 

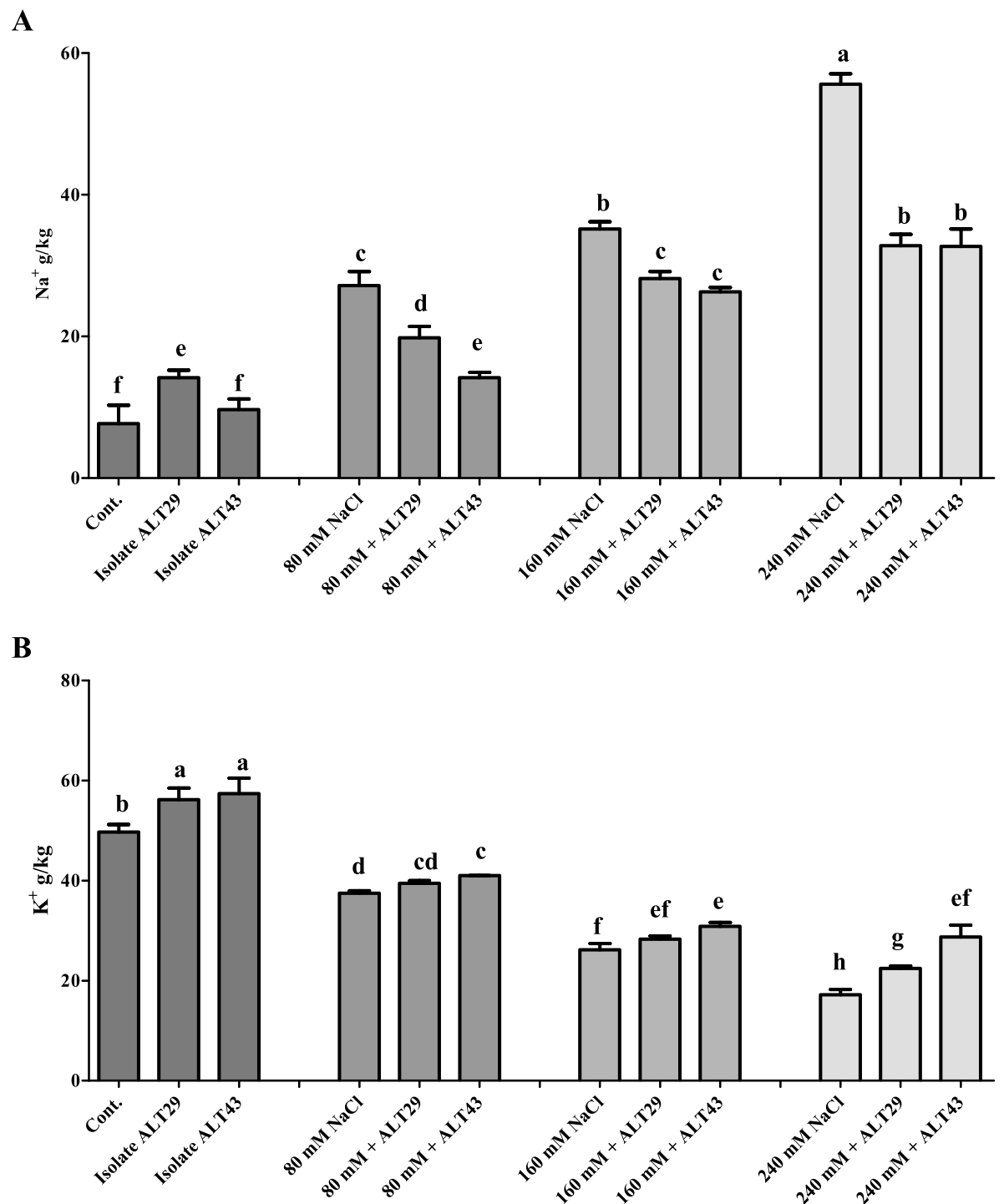

Fig. 6 Effects of bacterial isolates ALT29 and ALT43 on sodium $\left(\mathrm{Na}^{+}\right)$and potassium $\left(\mathrm{K}^{+}\right)$content. a: sodium content $\left(\mathrm{Na}^{+}\right)$; and b: Potassium $\left(\mathrm{K}^{+}\right)$ content in soybean plant under normal and $\mathrm{NaCl}$ stress. Data points are the mean of three technical replications and error bars represent standard error. Bars with different letters are significantly different from each other, as evaluated by DMRT analysis

were initially evaluated using Salkowski reagent (mix 2 $\mathrm{ml} 0.5 \mathrm{M} \mathrm{FeCl}_{3} ; 49 \mathrm{ml} 70 \%$ perchloric acid and $49 \mathrm{ml}$ $\mathrm{H}_{2} \mathrm{O}$ ) by adding $1 \mathrm{ml}$ supernatant and $1 \mathrm{ml}$ Salkowski reagent and kept in dark for 30 mints. The development of pink color indicated IAA production [27]. For phosphate solubilization Trypticase soy agar medium supplemented with $\mathrm{Ca}_{3} \quad\left(\mathrm{PO}_{4}\right)_{2}$ were used for phosphate solubilization, and the plates were incubated at $30^{\circ} \mathrm{C}$ for 7 days and observe the formation of transparent halos around each colony [27], while for and EPS formation Congo red assay was used [LB broth $(25 \mathrm{~g} / \mathrm{l})$, Congo red $(0.8 \mathrm{~g} / \mathrm{l})$, sucrose $(5 \%)$, agar $(2 \%)]$ were assessed according to the methods of and Yuna et al. [66] Furthermore for siderophore production, used chromeazurol "S" agar plates and incubate at $30^{\circ} \mathrm{C}$ for the appearance of orange halos in contrast to blue background [27]. Five concentrations of $\mathrm{NaCl}$ (purchased from DAEJUNG, Korea) were prepared $(0 \mathrm{mM}, 70 \mathrm{mM}, 140 \mathrm{mM}, 210 \mathrm{mM}$, and $280 \mathrm{mM}$ ). A $0.1 \%$ culture aliquot was inoculated into $100 \mathrm{ml}$ sterilized LB media and incubated at $30{ }^{\circ} \mathrm{C}$ in a shaking incubator before the bacterial density was measured at $600 \mathrm{~nm}$ using a spectrophotometer. Based on high salinity tolerance, isolates ALT29 and ALT43 were selected for further evaluation. For identification, genomic DNA and 16S rRNA-specific primers were used and amplified [61,67]. BLAST NCBI and EzTaxon program were used to determine the homology of different nucleotide sequences of the selected isolates and 

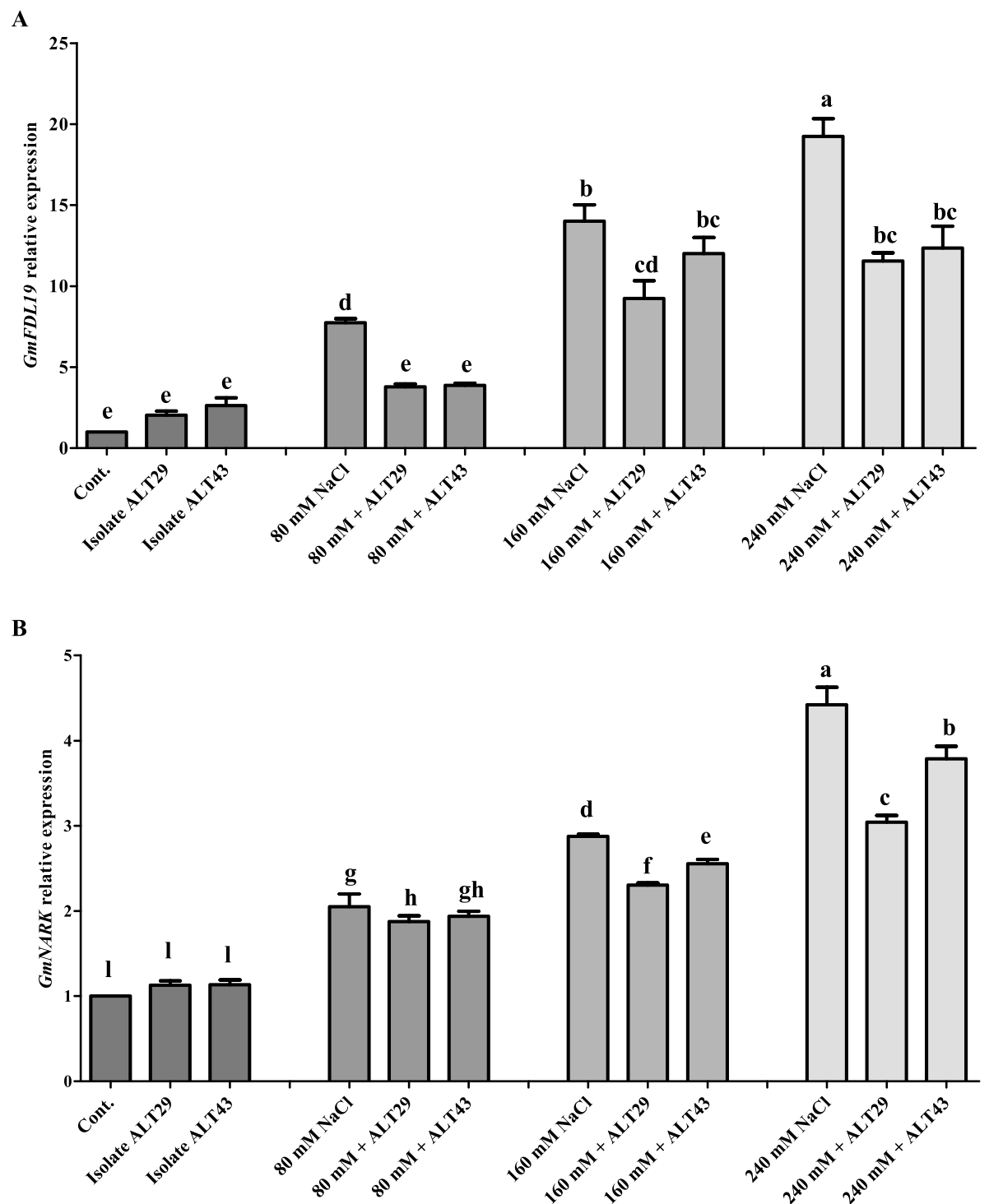

Fig. 7 Relative expression of GmFLD19 and GmNARK genes in soybean plants with and without inoculation of ALT29 and ALT 43 under NaCl stress. The values are means of three technical replicates calculated relative to those of actin gene expression. Error bars represent standard error. Bars with different letters are significantly different from each other, as evaluated by DMRT analysis

phylogenetic analysis was conducted using MEGA 6.1 software [68].

\section{ALT29 and ALT43 IAA and organic acid production}

Isolates ALT29 and ALT43 were grown in LB media for 3 days, centrifuged $\left(500 \times \mathrm{g}, 15 \mathrm{~min}\right.$ at $\left.4{ }^{\circ} \mathrm{C}\right)$, and analyzed to determine IAA and organic acid content. IAA analysis was conducted following the detailed method of Khan et al. [27]. Bacterial cultural filtrate was filtered through a $0.45 \mu \mathrm{m}$ cellulose acetate filter, acidified to $\mathrm{pH} 2.8$ and $50 \mu \mathrm{g} / \mathrm{ml}$ [D5]-IAA was added. Furthermore, the culture filtrates were then extracted three time with equal amount of ethyl acetate and completely evaporated through a rotary evaporator. Dried extract was re- dissolved in $5 \mathrm{ml} 0.1 \mathrm{M}$ acetic acid and then passed through reverse-phase $\mathrm{C} 18$ column. The methanol fractions were prepared by dissolving the residue in $1 \mathrm{ml}$ of methanol and add $1.5 \mathrm{ml}$ diazomethane. The methylated sample were re-dissolved in ethyl acetate and were analyzed by GC-MS SIM to determine IAA content (S. Table 2). The concentration of IAA in the broth was calculated by comparing the peak area of IAA with those of the known standard by GC-MS/SIM. To analyze the organic acid content, the bacterial culture broth was filtered through a $0.22 \mu \mathrm{l}$ Millipore filter (ADVANTE; DISMIC-25CS) and $10 \mu \mathrm{l}$ of each sample was injected into a high-performance liquid chromatography (HPLC: Shimadzu Co., Model Prominence) column [waters 
$600 \mathrm{E}$, included reflective Index detector, RI model RID10A, Column: PL Hi-Plex H $(7.7 \times 300 \mathrm{~mm})$. The isocratic condition for HPLC analysis $0.005 \mathrm{M} \mathrm{H} 2 \mathrm{SO} 4$ mobile phase, $0.6 \mathrm{ml} / \mathrm{mint}$ flow rate, $65^{\circ} \mathrm{C}$ temperature (S. Table 3). Retention times and peak areas of the chromatograms were compared with standards from SigmaAldrich, USA [61].

\section{Growth conditions and treatments}

Soybean seeds (Pungsannamulkong variety) were collected from the Soybean Genetic Resource Center (Kyungpook National University Daegu, Republic of Korea). First, seeds were surface-sterilized with $2.5 \%$ sodium hypochlorite for $15 \mathrm{~min}$ and washed thrice with autoclaved double-distilled water. The sterilized seeds were placed in plastic trays filled with horticulture substrate containing coco peat (45-50\%), perlite $(35-40 \%)$, peat moss (10-15\%), and zeolite (6-8\%), with $\mathrm{NO}_{3}(\sim$ $0.205 \mathrm{mg} / \mathrm{g}), \mathrm{KO}(\sim 0.1 \mathrm{mg} / \mathrm{g}), \mathrm{NH}^{+}(\sim 0.09 \mathrm{mg} / \mathrm{g})$, and PO $(\sim 0.35 \mathrm{mg} / \mathrm{g})$ [17]. The seedlings were grown in a growth chamber: day/night cycle $14 \mathrm{~h}$ at $30^{\circ} \mathrm{C} / 10 \mathrm{~h}$ at $25^{\circ} \mathrm{C}$; relative humidity $60-70 \%$; light intensity $250 \mu \mathrm{mol} / \mathrm{m}^{-2} \mathrm{~s}^{-1}$ for 10 days. At the VC stage (unrolled unifoliate leaves), equally-sized seedlings were selected and transferred to plastic pots $(10 \mathrm{~cm} \times 9 \mathrm{~cm})$ filled with the same horticulture substrate used in the germination trays.

The experimental design included (a) Control: wellwatered (b) Bacterial inoculated ALT29 and ALT43 (c) Treatment 1: $80 \mathrm{mM} \mathrm{NaCl}$ stress with or without isolate ALT29 and ALT43 (d) Treatment 2: $160 \mathrm{mM} \mathrm{NaCl}$ stress with or without isolate ALT29 and ALT43 and (e) Treatment 3: $240 \mathrm{mM} \mathrm{NaCl}$ stress with or without isolate ALT29 and ALT43. To test the plant-protection activity of ALT29 and ALT43 under $\mathrm{NaCl}$ stress, $50 \mathrm{ml}$ ALT29 and ALT43 $\left(4.0 \times 10^{8} \mathrm{cfu} / \mathrm{ml}\right)$ were inoculated via the drench method and distilled water was used for the control. After 2 weeks, growth attributes (root/shoot length), biomass (fresh/dry weight), and chlorophyll content were measured. A chlorophyll meter (SPAD-502 Minolta, Tokyo, Japan) was used for the chlorophyll measurements. The harvested plants were immediately frozen in liquid nitrogen and transferred to a $-80^{\circ} \mathrm{C}$ freeze dryer until further analysis. Following Khan et al. [60], Chlorophyll A and B and total carotenoid were extracted using $80 \%$ acetone and measured using a spectrophotometer at absorbances of $663 \mathrm{~nm}, 465 \mathrm{~nm}$, and $480 \mathrm{~nm}$. Chlorophyll a, b and carotenoid content was calculated using the following formulae:

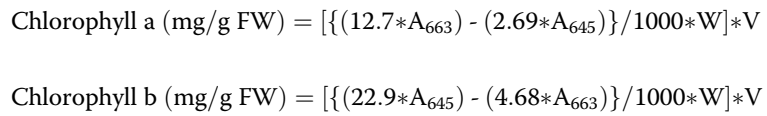

Carotenoids $(\mu \mathrm{g} / \mathrm{g} \mathrm{FW})=\mathrm{A}_{480}+\left(0.638 * \mathrm{~A}_{663}\right)-\left(0.638 * \mathrm{~A}_{645}\right)$

Where A+ Absorbance at respective wave length; $\mathrm{W}=$ fresh weight and $\mathrm{V}=$ extraction volume.

\section{Endogenous abscisic acid and salicylic acid quantification} Endogenous ABA was quantified and extracted according to Qi et al. [69]. For endogenous ABA analysis $3 \mathrm{mg}$ of powdered were treated with $30 \mathrm{ml}$ extraction solution (95\% isopropanol and 5\% glacial acetic acid) and $10 \mathrm{ng}$ of Me-[2H6]-ABA standard. The suspension was filtered, and the filtrate was concentrated using rotary evaporator. The residue was suspended in $4 \mathrm{ml}$ of $1 \mathrm{~N} \mathrm{NaOH}$ solution and rinsed trice with $3 \mathrm{ml}$ of methylene chloride in order to eliminate traces of lipophilic material. After decreasing the $\mathrm{pH}$ of aqueous phase to 3.5 by adding 6 $\mathrm{N} \mathrm{HCl}$, it was extracted through solvent extraction with ethyl acetate trice. The ethyl acetate extract were then evaporated and dry reside was re-suspended in phosphate buffer solution $(\mathrm{pH} \mathrm{8)}$, which was passed through polyvinylpolypyrrolidone (PVPP) column. The eluted phosphate buffer solution was once again partitioned 3 time with EtOAc after adjusting $\mathrm{pH} 3.5$ with $6 \mathrm{~N} \mathrm{HCl}$. All three aliquots extract were pooled and evaporate through rotary evaporator. The fraction was methylated with diazomethane for detection and $\mathrm{ABA}$ was quantified using GC-MS (6890 N network gas chromatograph, Agilent Technologies). Software from ThermoQuest Corp., Manchester, UK, was used to monitor signal ions (m/z 162 and 190 for Me-ABA; m/z 166 and 194 for Me-[2H6]-ABA) (S. Table 4). For the SA analysis, $0.2 \mathrm{~g}$ freeze-dried fine powder was mixed with $2 \mathrm{ml}$ of 90 and $100 \%$ methanol and centrifuged for $15 \mathrm{~min}$ at $10,000 \times \mathrm{g}$. The supernatant was evaporated in a vacuum and the sample was re-suspended in $3 \mathrm{ml}$ of $5 \%$ trichloroacetic acid. The upper organic layer was then mixed with a solution of isopropanol, ethyl acetate, and cyclopentane (49.5:49.5:1) and vigorously vortexed. The upper layer was transferred to a $4 \mathrm{ml}$ tube and vacuum dried. Prior to HPLC, the dried pellet was mixed with $1 \mathrm{ml}$ of HPLC mobile phase using Shimadzu device outfitted with fluorescence indicator (Shimadzu RF-10AxL) with excitation at $305 \mathrm{~nm}$ and emission at. SA was quantified using fluorescence detection (S. Table 5) [70, 71].

\section{Antioxidant enzyme activities}

For protein analysis, frozen plant tissues were ground using an ice-cold pestle and mortar and then added to a solution of $50 \mathrm{mM}$ phosphate-buffered saline, $0.1 \%$ polyvinylpyrrolidone (PVP), and $1 \mathrm{mM}$ ethylenediaminetetraacetic acid (EDTA). The homogenate was centrifuged at $10000 \times \mathrm{g}$ for $10 \mathrm{~min}$ at $4{ }^{\circ} \mathrm{C}$. The supernatant was immediately collected and used for protein and antioxidant enzyme quantification. Protein content was measured according to Bradford 
[72, 73] using BSA as a standard. Superoxide dismutase (SOD) activity was measured according to Khan et al. [60]. LPO, GSH, POD, and PPO activity were determined in accordance with the method described by Chaoui et al. [74] by measuring the absorbance at $290 \mathrm{~nm}, 470 \mathrm{~nm}$, and 420 $\mathrm{nm}$ using a T60 UV-Vis spectrophotometer. POD and PPO activity was determined using the guaiacol method [75], which was performed by adding $0.1 \mathrm{ml}$ supernatant to a reaction mixture containing $1.0 \mathrm{ml}$ of $2 \% \mathrm{H}_{2} \mathrm{O}_{2}, 2.9 \mathrm{ml}$ of 50 $\mathrm{mM}$ phosphate buffer (pH 5.5), and $1.0 \mathrm{ml}$ of $50 \mathrm{mM}$ guaiacol. Phosphate buffer was used as a control without enzymes. The absorbance was measured at $470 \mathrm{~nm}$ for $3 \mathrm{~min}$, and POD activity was calculated as the unit change per minute.

\section{RNA extraction, cDNA synthesis, and qRT-PCR analysis}

RNA extraction was performed following the protocol of Khan et al. [61]. Briefly total RNA was extracted using 1 $\mathrm{ml}$ Trizol $^{\odot}$ reagent (Invitrogen, USA), from $100 \mathrm{mg}$ crushed leaves of soybean, incubate at room temperature (10mint) and centrifuge (12,000 g; $\left.10 \mathrm{mint} ; 4^{\circ} \mathrm{C}\right)$. Supernatant were transfer to new tubes $(1.5 \mathrm{ml})$ and add $200 \mu$ chloroform, vortex vigorously (15 s), set on ice (3 mints) and again centrifuged (12,000 g; 15 mint; $4{ }^{\circ} \mathrm{C}$ ). Transfer upper layer $(300-400 \mu \mathrm{l})$ to new tube and add $500 \mu \mathrm{l}$ each of isoproponal and $1.2 \mathrm{M} \mathrm{NaCl} / 0.8 \mathrm{M} \mathrm{Na}$ Citrate, kept for 10 mints at room temperature and centrifuged $\left(12,000 \mathrm{~g} ; 10 \mathrm{mint} ; 4{ }^{\circ} \mathrm{C}\right)$. The pellet were washed with $1 \mathrm{ml} 75 \% \mathrm{EtOH}$ and centrifuged again (7500 g, 5 mint room temperature), discard supernatant and re-suspend the pellet in $40 \mu \mathrm{l}$ DEPC water. While A qPCRBIO cDNA Synthesis Kit from PCRBIOSYSTEMS was used for cDNA synthesis. qRT-PCR was performed using a qPCRBIO SYBER Green Kit from PCRBIOSYSTEM, using synthesized $(1 \mu \mathrm{l})$ of cDNAs as templates and the gene-specific primers. To normalize the level of relative expression of each gene, actin was used for each reaction and the expression level was calculated in control plants relatively with treated plants (S. Table 6). The reaction was performed in a $20 \mu \mathrm{l}$ volume containing $7 \mu \mathrm{l}$ ddH2O, $1 \mu \mathrm{l}$ primer, $10 \mu \mathrm{l}$ SYBER green and $1 \mu \mathrm{l}$ cDNA. A total sample volume of $50 \mu \mathrm{l}$ was subjected to the following condition: initial denaturation at $94{ }^{\circ} \mathrm{C}$ for 5 mint, 40 cycle of denaturation at $94{ }^{\circ} \mathrm{C}$ for $30 \mathrm{~s}$, annealing at $58{ }^{\circ} \mathrm{C}$ for $30 \mathrm{~s}$, extension at $72{ }^{\circ} \mathrm{C}$ for 1 mint and final extension at $72{ }^{\circ} \mathrm{C}$ for 5 mints $[76,77]$.

\section{Determination of $\mathrm{Na}$ and $\mathrm{K}$ uptake in plant}

$\mathrm{Na}$ and $\mathrm{K}$ content in shoots of bacterial-inoculated and non-inoculated plant samples in the $\mathrm{NaCl}$ treatments were investigated according to Khan et al. [61] using inductively coupled plasma mass spectrometry (ICP-MS; Optima 7900DV, Perkin-Elmer, USA).

\section{Statistical analysis}

The results were statistically evaluated by analysis of variance using SAS 9.4 software. All the experiments were repeated three times and data collect from each repetition were pooled together. All data present the mean values with standard error (SE). The mean were analyzed for significant differences among the treatments by using one-way analysis of variance (ANOVA), followed by Duncan's multiple range tests (DMRT) in SAS (V9.1, Cary, NC, USA).

\section{Abbreviations}

PGPB: Plant growth-promoting bacteria; IAA: Indole-3-acetic acid; ABA: Abscisic acid; SA: Salicylic acid; APX: Ascorbic acid peroxidase; SOD: Superoxide dismutase; GSH: Glutathione

\section{Supplementary Information}

The online version contains supplementary material available at https://doi. org/10.1186/s12870-021-02937-3.

Additional file 1.

\section{Acknowledgements}

Not applicable

Authors' contributions

MAK and AAS conducted the experiments. MAK, SA, and MH wrote the manuscript. MI, AA, and SMK conducted hormonal analyses. RJ and KMK conducted the qRT-PCR analysis. IJL designed, supervised, and financed the research. All authors have read and agreed to the content of the manuscript, which conforms to the journal's policies. The author (s) read and approved the final manuscript.

\section{Funding}

This research was supported by Basic Science Research Program through the National Research Foundation of Korea (NRF) funded by the Ministry of Education (2017R1D1A1B04035601). The funding body had no role in the design of the study, collection, analysis, and interpretation of data, and writing the manuscript.

Availability of data and materials

The dataset generated or analyzed and strain used in the current study were submitted to NCBI with the GenBank accession no. MW077246 and MW077247.

\section{Declarations}

Ethics approval and consent to participate

Not applicable

Consent for publication

Not applicable.

\section{Competing interests}

The authors declare no competing interests.

\section{Author details}

${ }^{1}$ School of Applied Biosciences, Kyungpook National University, Daegu 41566, Republic of Korea. ${ }^{2}$ Natural and Medical Plants Research center, University of Nizwa, 616 Nizwa, Oman. ${ }^{3}$ Department of Botany, Abdul Wali Khan University, Mardan, Pakistan. 
Received: 23 December 2020 Accepted: 25 March 2021 Published online: 12 April 2021

\section{References}

1. Chung YS, Kim KS, Hamayun M, Kim Y. Silicon confers soybean resistance to salinity stress through regulation of reactive oxygen and reactive nitrogen species. Front Plant Sci. 2019;10:1725.

2. Yoon JY, Hamayun M, Lee S-K, Lee I-J. Methyl jasmonate alleviated salinity stress in soybean. J Crop Sci Biotechnol. 2009;12(2):63-8. https://doi.org/10.1 007/s12892-009-0060-5.

3. Hamayun $M$, Khan SA, Khan AL, Shinwari ZK, Hussain J, Sohn E-Y, et al Effect of salt stress on growth attributes and endogenous growth hormones of soybean cultivar Hwangkeumkong. Pak J Bot. 2010;42(5): 3103-12.

4. Jamil A, Riaz S, Ashraf M, Foolad MR. Gene expression profiling of plants under salt stress. Crit Rev Plant Sci. 2011;30(5):435-58. https://doi.org/10.1 080/07352689.2011.605739.

5. Hamayun M, Khan SA, Khan AL, Shin J-H, Ahmad B, Shin D-H, et al. Exogenous gibberellic acid reprograms soybean to higher growth and salt stress tolerance. J Agric Food Chem. 2010;58(12):7226-32. https://doi.org/1 $0.1021 /$ jf101221t.

6. Almeida DM, Oliveira MM, Saibo NJM. Regulation of Na+ and K+ homeostasis in plants: towards improved salt stress tolerance in crop plants. Genet Mol Biol. 2017;40(1 suppl 1):326-45. https://doi.org/10.1590/1678-4 685-gmb-2016-0106.

7. Roy SJ, Negrao S, Tester M. Salt resistant crop plants. Curr Opin Biotechnol. 2014;26:115-24. https://doi.org/10.1016/j.copbio.2013.12.004.

8. Gao Y, Lu Y, Wu M, Liang E, Li Y, Zhang D, et al. Ability to remove Na+ and retain $\mathrm{K}+$ correlates with salt tolerance in two maize inbred lines seedlings. Front Plant Sci. 2016:7(1716).

9. Assaha DVM, Ueda A, Saneoka H, Al-Yahyai R, Yaish MW. The role of $\mathrm{Na}(+)$ and $\mathrm{K}(+)$ transporters in salt stress adaptation in glycophytes. Front Physiol. 2017;8:509. https://doi.org/10.3389/fphys.2017.00509.

10. Tavakkoli E, Rengasamy P, McDonald GK. High concentrations of $\mathrm{Na}+$ and $\mathrm{Cl}$ - ions in soil solution have simultaneous detrimental effects on growth of faba bean under salinity stress. J Exp Bot. 2010;61(15):4449-59. https://doi. org/10.1093/jxb/erq251.

11. Demetriou G, Neonaki C, Navakoudis E, Kotzabasis K. Salt stress impact on the molecular structure and function of the photosynthetic apparatus-the protective role of polyamines. Biochim Biophys Acta. 2007;1767(4):272-80. https://doi.org/10.1016/j.bbabio.2007.02.020.

12. Lu C, Vonshak A. Effects of salinity stress on photosystem II function in cyanobacterial Spirulina platensis cells. Physiol Plant. 2002;114(3):405-13. https://doi.org/10.1034/j.1399-3054.2002.1140310.x.

13. Misra AN, Srivastava A, Strasser RJ. Utilization of fast chlorophyll a fluorescence technique in assessing the salt/ion sensitivity of mung bean and Brassica seedlings. J Plant Physiol. 2001;158(9):1173-81. https://doi.org/1 0.1078/S0176-1617(04)70144-3.

14. Hniličková H, Hnilička F, Martinkova J, Kraus K. Effects of salt stress on water status, photosynthesis and chlorophyll fluorescence of rocket. Plant Soil Environ. 2017;63(8):362-7.

15. Li Y, Chen Q, Nan H, Li X, Lu S, Zhao X, et al. Overexpression of GmFDL19 enhances tolerance to drought and salt stresses in soybean. PLoS One. 2017;12(6):e0179554. https://doi.org/10.1371/journal.pone.0179554.

16. Shu K, Qi Y, Chen F, Meng Y, Luo X, Shuai H, et al. Salt stress represses soybean seed germination by negatively regulating GA biosynthesis while positively mediating ABA biosynthesis. Front Plant Sci. 2017; 8(1372).

17. Khan MA, Asaf S, Khan AL, Jan R, Kang S-M, Kim K-M, et al. Rhizobacteria AK1 remediates the toxic effects of salinity stress via regulation of endogenous phytohormones and gene expression in soybean. Biochem J. 2019:476(16):2393-409. https://doi.org/10.1042/BCJ20190435.

18. Khan MA, Ullah I, Waqas M, Hamayun M, Khan AL, Asaf S, et al. Halo-tolerant rhizospheric Arthrobacter woluwensis AK1 mitigates salt stress and induces physio-hormonal changes and expression of GmST1 and GmLAX3 in soybean. Symbiosis. 2019;77(1):9-21. https://doi.org/10.1007/s13199-0180562-3.

19. Khan MA, Asaf S, Khan AL, Ullah I, Ali S, Kang S-M, et al. Alleviation of salt stress response in soybean plants with the endophytic bacterial isolate Curtobacterium sp. SAK1. Ann Microbiol. 2019.
20. Ren S, Lyle C, Jiang GL, Penumala A. Soybean salt tolerance 1 (GmST1) reduces ROS production, enhances ABA sensitivity, and abiotic stress tolerance in Arabidopsis thaliana. Front Plant Sci. 2016;7:445.

21. Li S, Wang N, Ji D, Zhang W, Wang Y, Yu Y, et al. A GmSIN1/GmNCED3s/ GmRbohBs feed-forward loop acts as a signal amplifier that regulates root growth in soybean exposed to salt stress. Plant Cell. 2019;31(9):2107-30. https://doi.org/10.1105/tpc.18.00662.

22. Cheng C, Li C, Wang D, Zhai L, Cai Z. The soybean GmNARK affects ABA and salt responses in transgenic Arabidopsis thaliana. Front Plant Sci. 2018; 9(514).

23. Khan MA, Asaf S, Khan AL, Adhikari A, Jan R, Ali S, et al. Halotolerant rhizobacterial strains mitigate the adverse effects of $\mathrm{NaCl}$ stress in soybean seedlings. Biomed Res Int. 2019;2019.

24. Shokat S, Großkinsky DK. Tackling salinity in sustainable agriculture-what developing countries may learn from approaches of the developed world. Sustainability. 2019;11(17):4558. https://doi.org/10.3390/su11174558.

25. Ladeiro B. Saline agriculture in the 21 st century: using salt contaminated resources to cope food requirements. J Bot. 2012;2012:310705.

26. Fatma M, Asgher M, Masood A, Khan NA. Excess sulfur supplementation improves photosynthesis and growth in mustard under salt stress through increased production of glutathione. Environ Exp Bot. 2014;107:55-63. https://doi.org/10.1016/j.envexpbot.2014.05.008.

27. Khan MA, Asaf S, Khan AL, Adhikari A, Jan R, Ali S, et al. Plant growthpromoting endophytic bacteria augment growth and salinity tolerance in rice plants. Plant Biol. 2020.

28. Kumar A, Singh S, Gaurav AK, Srivastava S, Verma JP. Plant growthpromoting bacteria: biological tools for the mitigation of salinity stress in plants. Front Microbiol. 2020;11(1216).

29. Kang S-M, Shahzad R, Bilal S, Khan AL, Park Y-G, Lee K-E, et al. Indole-3acetic-acid and ACC deaminase producing Leclercia adecarboxylata MO1 improves Solanum lycopersicum L. growth and salinity stress tolerance by endogenous secondary metabolites regulation. BMC Microbiol. 2019;19(1): 80. https://doi.org/10.1186/s12866-019-1450-6.

30. Kang S-M, Khan A, Waqas M, You Y-H, Kim J-H, Kim J-G, et al. Plant growth promoting rhizobacterias reduces adverse effects of salinity and osmotic stress by regulating phytohormones and antioxidants in Cucumis sativus. J Plant Interact. 2014;9(1):673-82. https://doi.org/10.1080/17429145.2014.894 587.

31. Nadeem SM, Zahir ZA, Naveed M, Asghar HN, Arshad M. Rhizobacteria capable of producing ACC-deaminase may mitigate salt stress in wheat. Soil Sci Soc Am J. 2010;74(2):533-42. https://doi.org/10.2136/sssaj2008.0240.

32. Barnawal D, Bharti N, Pandey SS, Pandey A, Chanotiya CS, Kalra A. Plant growth-promoting rhizobacteria enhance wheat salt and drought stress tolerance by altering endogenous phytohormone levels and TaCTR1/ TaDREB2 expression. Physiol Plant. 2017;161(4):502-14. https://doi.org/1 $0.1111 /$ ppl.12614.

33. Yoo SJ, Weon HY, Song J, Sang MK. Induced tolerance to salinity stress by halotolerant bacteria bacillus aryabhattai H19-1 and B. mesonae H2O-5 in tomato plants. J Microbiol Biotechnol. 2019;29(7):1124-36. https://doi.org/1 0.4014/jmb.1904.04026.

34. Yasmin H, Naeem S, Bakhtawar M, Jabeen Z, Nosheen A, Naz R, et al. Halotolerant rhizobacteria Pseudomonas pseudoalcaligenes and Bacillus subtilis mediate systemic tolerance in hydroponically grown soybean (Glycine max L.) against salinity stress. PLoS ONE. 2020;15(4):e0231348.

35. Tiwari S, Prasad V, Chauhan PS, Lata C. Bacillus amyloliquefaciens confers tolerance to various abiotic stresses and modulates plant response to phytohormones through osmoprotection and gene expression regulation in rice. Front Plant Sci. 2017:8(1510).

36. Yao L, Wu Z, Zheng Y, Kaleem I, Li C. Growth promotion and protection against salt stress by Pseudomonas putida Rs-198 on cotton. Eur J Soil Biol. 2010;46(1):49-54. https://doi.org/10.1016/j.ejsobi.2009.11.002.

37. Heidari M. Effects of salinity stress on growth, chlorophyll content and osmotic components of two basil (Ocimum basilicum L.) genotypes. Afr J Biotechnol. 2012;11(2):379-84.

38. Yang Z, Li J-L, Liu L-N, Xie Q, Sui N. Photosynthetic regulation under salt stress and salt-tolerance mechanism of sweet sorghum. Front Plant Sci. 2020;10(1722)

39. Heidari M, Golpayegani A. Effects of water stress and inoculation with plant growth promoting rhizobacteria (PGPR) on antioxidant status and photosynthetic pigments in basil (Ocimum basilicum L.). J Saudi Soc Agric Sci. 2012;11(1):57-61. https://doi.org/10.1016/j.jssas.2011.09.001. 
40. Gusain YS, Singh U, Sharma A. Bacterial mediated amelioration of drought stress in drought tolerant and susceptible cultivars of rice (Oryza sativa L.). Afr J Biotechnol. 2015;14(9):764-73.

41. Siddikee MA, Chauhan PS, Anandham R, Han G-H, Sa T-M. Isolation, characterization, and use for plant growth promotion under salt stress, of ACC deaminase-producing halotolerant bacteria derived from coastal soil. J Microbiol Biotechnol. 2010;20(11):1577-84. https://doi.org/10.4014/ jmb.1007.07011.

42. Fan P, Chen D, He Y, Zhou Q, Tian Y, Gao L. Alleviating salt stress in tomato seedlings using Arthrobacter and Bacillus megaterium isolated from the rhizosphere of wild plants grown on saline-alkaline lands. Int J Phytoremediation. 2016;18(11):1113-21. https://doi.org/10.1080/15226514.2 016.1183583.

43. Vurukonda SSKP, Vardharajula S, Shrivastava M, SkZ A. Enhancement of drought stress tolerance in crops by plant growth promoting rhizobacteria. Microbiol Res. 2016;184:13-24. https://doi.org/10.1016/j. micres.2015.12.003.

44. Selvakumar G, Panneerselvam P, Ganeshamurthy AN. Bacterial mediated alleviation of abiotic stress in crops. In: Bacteria in agrobiology: stress management: Springer; 2012. p. 205-24.

45. Gupta S, Schillaci M, Walker R, Smith PMC, Watt M, Roessner U. Alleviation of salinity stress in plants by endophytic plant-fungal symbiosis: current knowledge, perspectives and future directions. Plant Soil. 2020. https://doi. org/10.1007/s11104-020-04618-w.

46. Wang M, Zheng Q, Shen Q, Guo S. The critical role of potassium in plant stress response. Int J Mol Sci. 2013;14(4):7370-90. https://doi.org/10.3390/ ijms 14047370

47. He T, Cramer GR. Abscisic acid concentrations are correlated with leaf area reductions in two salt-stressed rapid-cycling Brassica species. Plant Soil. 1996;179(1):25-33. https://doi.org/10.1007/BF00011639.

48. Cramer GR, Quarrie SA. Abscisic acid is correlated with the leaf growth inhibition of four genotypes of maize differing in their response to salinity. Funct Plant Biol. 2002;29(1):111-5. https://doi.org/10.1071/ PP01131.

49. Mulholland BJ, Taylor IB, Jackson AC, Thompson AJ. Can ABA mediate responses of salinity stressed tomato. Environ Exp Bot. 2003;50(1):17-28. https://doi.org/10.1016/S0098-8472(02)00110-7.

50. Santner A, Estelle M. Recent advances and emerging trends in plant hormone signalling. Nature. 2009;459(7250):1071-8. https://doi.org/10.1038/ nature08122.

51. Montero E, Cabot C, Poschenrieder C, Barcelo J. Relative importance of osmotic-stress and ion-specific effects on ABA-mediated inhibition of leaf expansion growth in Phaseolus vulgaris. Plant Cell Environ. 1998;21(1):54-62. https://doi.org/10.1046/j.1365-3040.1998.00249.x.

52. Park Y-G, Mun B-G, Kang S-M, Hussain A, Shahzad R, Seo C-W, et al. Bacillus aryabhattai SRBO2 tolerates oxidative and nitrosative stress and promotes the growth of soybean by modulating the production of phytohormones. PLoS One. 2017;12(3):e0173203. https://doi.org/10.1371/ journal.pone.0173203.

53. Curá JA, Franz DR, Filosofía JE, Balestrasse KB, Burgueño LE. Inoculation with Azospirillum sp. and Herbaspirillum sp. bacteria increases the tolerance of maize to drought stress. Microorganisms. 2017;5(3):41.

54. Nlangumaran G, Smith DL. Plant growth promoting rhizobacteria in amelioration of salinity stress: a systems biology perspective. Front Plant Sci. 2017;8(1768).

55. Wang Q-J, Sun H, Dong Q-L, Sun T-Y, Jin Z-X, Hao Y-J, et al. The enhancement of tolerance to salt and cold stresses by modifying the redox state and salicylic acid content via the cytosolic malate dehydrogenase gene in transgenic apple plants. Plant Biotechnol J. 2016;14(10):1986-97. https://doi.org/10.1111/pbi.12556.

56. Yang Y, Qi M, Mei C. Endogenous salicylic acid protects rice plants from oxidative damage caused by aging as well as biotic and abiotic stress. Plant J. 2004;40(6):909-19. https://doi.org/10.1111/j.1365-313X.2 004.02267.x.

57. Radhakrishnan R, Lee I-J. Regulation of salicylic acid, jasmonic acid and fatty acids in cucumber (Cucumis sativus L.) by spermidine promotes plant growth against salt stress. Acta Physiol Plant. 2013;35(12):3315-22. https:// doi.org/10.1007/s11738-013-1364-0.

58. Wang $Y$, Mopper $\mathrm{S}$, Hasenstein $\mathrm{KH}$. Effects of salinity on endogenous ABA, IAA, JA, and SA in Iris hexagona. J Chem Ecol. 2001;27(2):327-42. https://doi. org/10.1023/A:1005632506230.
59. Kang S-M, Khan AL, Waqas M, You Y-H, Kim J-H, Kim J-G, et al. Plant growth-promoting rhizobacteria reduce adverse effects of salinity and osmotic stress by regulating phytohormones and antioxidants in Cucumis sativus. J Plant Interact. 2014;9(1):673-82. https://doi.org/10.1080/17429145.2 014.894587.

60. Khan MA, Asaf S, Khan AL, Jan R, Kang S-M, Kim K-M, et al. Thermotolerance effect of plant growth-promoting Bacillus cereus SA1 on soybean during heat stress. BMC Microbiol. 2020;20(1):175. https://doi.org/10.1186/s12866-02 0-01822-7.

61. Khan MA, Asaf S, Khan AL, Jan R, Kang S-M, Kim K-M, et al. Extending thermotolerance to tomato seedlings by inoculation with SA1 isolate of Bacillus cereus and comparison with exogenous humic acid application. PLoS One. 2020;15(4):e0232228. https://doi.org/10.1371/journal.pone. 0232228 .

62. Kiani S, Babaeianjelodar N, Bagheri N, Najafizarrini H. Effect of mannitol stress on morphological, biochemical and polyphenol parameters in broccoli sprouts (Brassica oleracea var. Italica). Appl Ecol Environ Res. 2018; 16(2):2043-58. https://doi.org/10.15666/aeer/1602_20432058.

63. Sandhya V, Ali SZ, Grover M, Reddy G, Venkateswarlu B. Effect of plant growth promoting Pseudomonas spp. on compatible solutes, antioxidant status and plant growth of maize under drought stress. Plant Growth Regul. 2010;62(1):21-30. https://doi.org/10.1007/s10725-010-9479-4.

64. Vardharajula S, Ali SZ, Grover M, Reddy G, Bandi V. Drought-tolerant plant growth promoting Bacillus spp.: effect on growth, osmolytes, and antioxidant status of maize under drought stress. J Plant Interact. 2011;6(1): 1-14. https://doi.org/10.1080/17429145.2010.535178.

65. Nan H, Cao D, Zhang D, Li Y, Lu S, Tang L, et al. GmFT2a and GmFT5a redundantly and differentially regulate flowering through interaction with and upregulation of the bZIP transcription factor GmFDL19 in soybean. PLoS One. 2014;9(5):e97669. https://doi.org/10.1371/journal. pone.0097669.

66. Yu-Na K, Muhammad Aaqil K, Sang-Mo K, Muhammad H, In-Jung L. Enhancement of drought-stress tolerance of Brassica oleracea var. italica L. by newly isolated variovorax sp. YNA59. J Microbiol Biotechnol. 2020;0(0)

67. Sambrook J, Russell D. Molecular cloning: a laboratory manual. 3rd ed. Cold Spring Harbor: Cold Spring Harbor Laboratory Press; 2001.

68. Tamura K, Stecher G, Peterson D, Filipski A, Kumar S. MEGA6: molecular evolutionary genetics analysis version 6.0. Mol Biol Evol. 2013;30(12):2725-9. https://doi.org/10.1093/molbev/mst197.

69. Qi Q, Rose PA, Abrams GD, Taylor DC, Abrams SR, Cutler AJ. (+)-Abscisic acid metabolism, 3-ketoacyl-coenzyme a synthase gene expression, and very-long-chain monounsaturated fatty acid biosynthesis inBrassica napus embryos. Plant Physiol. 1998;117(3):979-87. https://doi.org/10.1104/pp.117.3. 979.

70. Jan R, Khan MA, Asaf S, Lubna, Lee I-J, Kim KM. Metal resistant endophytic bacteria reduces cadmium, nickel toxicity, and enhances expression of metal stress related genes with improved growth of Oryza Sativa, via regulating its antioxidant machinery and endogenous hormones. Plants. 2019;8(10):363. https://doi.org/10.3390/plants8100363.

71. Waqas M, Khan A, Hamayun M, Shahzad R, Kim Y-H, Choi K-S, et al. Endophytic infection alleviates biotic stress in sunflower through regulation of defence hormones, antioxidants and functional amino acids. Eur J Plant Pathol. 2015;141(4):803-24. https://doi.org/10.1007/s1 0658-014-0581-8.

72. Bradford MM. A rapid and sensitive method for the quantitation of microgram quantities of protein utilizing the principle of protein-dye binding. Anal Biochem. 1976;72(1-2):248-54. https://doi.org/10.1016/0003-2 697(76)90527-3

73. Hamayun $M$, Hussain $A$, Khan $S A$, Kim H-Y, Khan AL, Waqas $M$, et al. Gibberellins producing endophytic fungus porostereum spadiceum AGH786 rescues growth of salt affected soybean. Front Microbiol. $2017 ; 8(686)$

74. Chaoui A, Mazhoudi S, Ghorbal MH, El Ferjani E. Cadmium and zinc induction of lipid peroxidation and effects on antioxidant enzyme activities in bean (Phaseolus vulgaris L.). Plant Sci. 1997;127(2):139-47. https://doi. org/10.1016/S0168-9452(97)00115-5.

75. Zhang J, Kirkham MB. Drought-stress-induced changes in activities of superoxide dismutase, catalase, and peroxidase in wheat species. Plant Cell Physiol. 1994;35(5):785-91. https://doi.org/10.1093/oxfordjournals.pcp.a 078658 . 
76. Jan R, Khan MA, Asaf S, Lee I-J, Bae J-S, Kim K-M. Overexpression of OsCM alleviates BLB stress via phytohormonal accumulation and transcriptional modulation of defense-related genes in Oryza sativa. Sci Rep. 2020;10(1): 19520. https://doi.org/10.1038/s41598-020-76675-1.

77. Jan R, Khan MA, Asaf S, Lee I-J, Kim K-M. Overexpression of OsF3H modulates WBPH stress by alteration of phenylpropanoid pathway at a transcriptomic and metabolomic level in Oryza sativa. Sci Rep. 2020;10(1): 14685. https://doi.org/10.1038/s41598-020-71661-z.

\section{Publisher's Note}

Springer Nature remains neutral with regard to jurisdictional claims in published maps and institutional affiliations.

Ready to submit your research? Choose BMC and benefit from:

- fast, convenient online submission

- thorough peer review by experienced researchers in your field

- rapid publication on acceptance

- support for research data, including large and complex data types

- gold Open Access which fosters wider collaboration and increased citations

- maximum visibility for your research: over $100 \mathrm{M}$ website views per year

At $B M C$, research is always in progress.

Learn more biomedcentral.com/submissions 